\title{
Diálogos entre justiça restaurativa e o Direito Juvenil Brasileiro com enfoque em adolescentes autores de atos infracionais
}

\author{
Dialogues between restorative justice and Brazilian \\ juvenile law with a focus on adolescent authors of \\ illegal acts
}

\begin{abstract}
Resumo: Buscou-se nesse trabalho estabelecer uma interface entre o direito juvenil brasileiro e a justiça restaurativa a partir da análise bibliográfica da doutrina e legislação referentes a ambas as temáticas, com enfoque nos direitos dos adolescentes autores de atos infracionais. Enquanto meio de solução de conflitos, que resultem ou não em crimes e atos infracionais, a abordagem da justiça restaurativa se contrapõe à abordagem dos sistemas penais convencionais, cujo enfoque, baseado no paradigma retributivo, reside na culpabilização e punição do infrator. Isso porque a proposta da abordagem restaurativa fundamenta-se na criação de um espaço para que a reparação, à medida do possível, do dano ocasionado à vítima pelo infrator, possa ocorrer. Esse processo se dá por meio do diálogo, fundado na alteridade e na horizontalidade dos participantes das práticas restaurativas. Assim, buscou-se compreender a temática da justiça restaurativa e do direito juvenil, com enfoque na legislação aplicável ao adolescente autor de ato infracional, separadamente, para que posteriormente uma interface entre eles pudesse ser realizada. Concluiu-se que o sistema de justiça juvenil se relaciona com a proposta da justiça restaurativa, ao oferecer uma gama de institutos jurídicos e aporte teórico para que essa forma de solução de conflitos possa ser aplicada em adolescentes autores de atos infracionais.
\end{abstract}

Natália de Souza Neves ${ }^{1}$

Palavras-chave: Justiça restaurativa. Sistema de justiça juvenil. Direito Brasileiro.

\begin{abstract}
This work aims at establishing an interface between Brazilian juvenile law and restorative justice basing on an bibliographic analysis of the doctrine and legislation referring to both themes, focusing on the rights of adolescents who commit crimes. As a means of resolving conflicts, regardless of whether they result in crimes and infractions, the approach of restorative justice is critical of the approach of conventional penal systems, whose focus, based on the retributive paradigm, lies in the guilt and punishment of the offender. This is because the proposal of the restorative approach focuses on settling a moment for reparation, as far as possible, of the damage caused to the victim by the offender. This process occurs on a dialogue basis, founded on the alterity and equality of the participants
\end{abstract}

\footnotetext{
${ }^{1}$ Doutoranda em Direito na Universidade Federal de Minas Gerais (UFMG), com período sanduíche junto à Universidade de Alberta (Canadá). Mestre em Direito pela Universidade Federal de Minas Gerais (UFMG). Graduada em Letras e Direito pela Universidade Federal de Uberlândia (UFU). ORCID n. 0000-0002-2529-0636.
} 


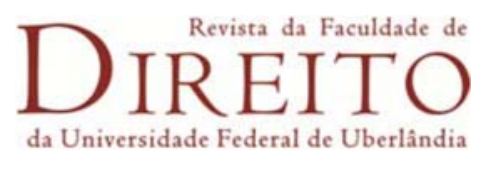

involved on a restorative practice. Thus, we aimed at understanding the theme of restorative justice and juvenile law separately, focusing on the legislation applicable to the adolescents who commit crimes, so that afterwards an interface between them could be made. It was concluded that the juvenile justice system relates to the proposal of restorative justice, by offering a range of legal institutes and theoretical input so that this form of conflict resolution can be applied in adolescent authors of illegal acts.

Keywords: Restorative justice. Juvenile justice system. Brazilian Law.

\section{Introdução}

A justiça restaurativa, compreendida como uma abordagem diferenciada para se lidar com conflitos, crimes e atos infracionais ${ }^{2}$, tem ganhado importante enfoque nas reformas dos sistemas de justiça penais convencionais. Esses sistemas encontram-se fundados no paradigma de justiça retributivo, o que implica na priorização de alguns elementos, como a culpabilização e a penalização dos infratores. Não obstante, as respostas oferecidas, calcadas nesse paradigma, têm sido insatisfatórias para responder à criminalidade e reincidência de crimes e atos infracionais cometidos por adultos e adolescentes, respectivamente.

De acordo com dados divulgados por meio do Levantamento Nacional de Informações Penitenciárias (BRASIL, 2017), o total da população prisional em junho de 2017 no Brasil chegava a 726.354, sendo que o déficit de vagas era de 303.112. O Brasil chega a ocupar o terceiro lugar no ranking de países com maior número de presos no mundo, sendo superado pelos Estados Unidos e China, conforme dados disponibilizados pelo Ministério da Segurança Pública em 2016. Com relação à realidade dos adolescentes em conflito com a lei, o contexto também não é animador, considerando o nível de reincidência de atos infracionais no país, constatado em pesquisa realizada pelo Conselho Nacional de Justiça em 2012 (CNJ, 2012).

\footnotetext{
${ }^{2}$ Conforme apregoa o art. 103 do Estatuto da Criança e do Adolescente (ECA), considera-se ato infracional a conduta descrita como crime ou contravenção penal. Esses atos são praticados por adolescentes, de idade compreendida entre 12 a 18 anos.
} 


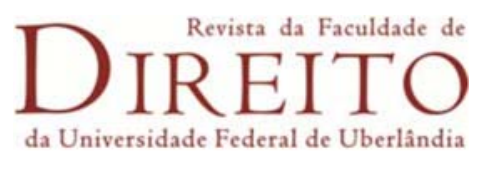

Diante desse cenário, faz-se mister a reflexão sobre os paradigmas e parâmetros legais sobre os quais o sistema penal e o sistema de justiça juvenil brasileiros estão embasados. Essa reflexão é importante para que soluções possam ser pensadas. Soluções que considerem a responsabilização pelo crime e ato infracional não numa perspectiva individualizante, somente, mas também coletiva, que envolva a participação das partes, do Estado e da sociedade civil. A responsabilização coletiva é reforçada precipuamente no caso de adolescentes em conflito com a lei, uma vez que o texto constitucional (Constituição Federal, art. 227) e o Estatuto da Criança e do Adolescente (ECA, art. $4^{\circ}$ ) apregoam a responsabilidade coletiva da família, da sociedade e do Estado em zelarem pelos direitos das crianças e dos adolescentes.

Nesse trabalho buscou-se compreender a justiça restaurativa como método de solução de conflitos e infrações, com enfoque em atos infracionais cometidos por adolescentes. Para tanto, primeiramente optou-se por compreender o paradigma sobre o qual o sistema de justiça penal brasileiro encontra-se embasado, visto que este sistema possui uma interface e influência sobre o sistema de justiça juvenil ${ }^{3}$, que define como ato infracional a conduta cometida como crime ou contravenção penal. Posteriormente, abordou-se o contexto de surgimento e as configurações da justiça restaurativa, com o intuito de se compreender essa forma de solução de conflitos, que resultem ou não em atos infracionais. Por fim, buscou-se

\footnotetext{
${ }^{3}$ A adoção de um Direito Penal Juvenil no Brasil é matéria controversa. O adolescente, ao cometer ato infracional, poderá receber uma das medidas socioeducativas previstas no art. 112 do Estatuto da Criança e do Adolescente. A execução dessas medidas encontra-se regulamentada pela Lei n. ${ }^{\circ}$ 12.594/2012, que institui o Sistema Nacional de Atendimento Socioeducativo (SINASE). Muito embora a execução das medidas socioeducativas tenha objetivos e princípios que lhes são próprios, é importante destacar que há a utilização na legislação aplicada aos adolescentes autores de atos infracionais de dispositivos utilizados sistema de justiça penal, como por exemplo a definição de ato infracional, que corresponde à conduta descrita como crime ou contravenção penal, e a previsão da medida socioeducativa de privação de liberdade. Não obstante, advoga-se que os princípios e objetivos instituídos pelo SINASE são específicos e delimitados, sendo que o paradigma teórico que fundamenta os direitos desses adolescentes é o paradigma da proteção integral. Esse paradigma estatui a proteção integral dos direitos fundamentais dos adolescentes, incluindo-se aqueles autores de atos infracionais, sendo que a socioeducação torna-se, nesse contexto, um objetivo a ser atingido pelo sistema socioeducativo.
} 


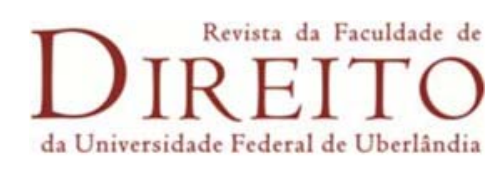

analisar os fundamentos da aplicação da justiça restaurativa no sistema de justiça juvenil brasileiro, à luz da análise da doutrina e legislação brasileiras referentes ao tema.

\section{Em busca de um paradigma}

Ao se conceituar a justiça restaurativa como meio não-adversarial de solução de conflitos, crimes e atos infracionais, faz-se necessário primeiramente recorrer ao conceito de paradigma, visto que a justiça restaurativa representa um novo paradigma para o tratamento de conflitos, judicializados ou não.

Segundo Thomas Kuhn, um paradigma é o conjunto de problemas e soluções modelares que os membros de uma comunidade científica partilham (KUHN, 1998, p. 13). Entretanto, o paradigma não deve limitar a atividade científica, mas apenas orientá-la. A ocorrência de limitações é um sinal de que os paradigmas estão sendo superados pela realidade e pelos fatos. Esta situação de crise provoca a necessidade de sua própria revisão.

Nessa perspectiva, nossa concepção de ciência, sejam elas naturais ou sociais, encontra-se eivada de pré-conceitos, arquétipos da realidade, que moldam os processos da pesquisa, tais como a seleção de concepções teóricas e linhas de intervenção, a metodologia com a qual interpretamos dados, construímos hipóteses e nos posicionamos face ao objeto de estudo e à realidade na qual ele se insere. Assim, obedecemos a paradigmas que:

[...] moldam nossa abordagem não apenas do mundo físico, mas também do mundo social, psicológico e filosófico. Eles são a lente através das quais compreendemos os fenômenos. Eles determinam a forma como resolvemos os problemas (ZEHR, 2008, p. 83).

As concepções de justiça e as formas de solução de conflitos, crimes e atos infracionais também se encontram permeadas de paradigmas. Nesse trabalho, destaca-se o paradigma da justiça retributiva, "que se apresenta 
como uma forma específica de organizar a realidade" (ZEHR, 2008, p. 83) assim como o paradigma proposto pela justiça restaurativa, que, alternativamente ao paradigma da justiça retributiva, toma como referência central as pessoas e os relacionamentos para a busca de soluções para os conflitos, judicializados ou não.

Segundo o paradigma da justiça retributiva, que se apresenta como principal referência para os sistemas de justiça penais convencionais, dentre eles o sistema penal brasileiro, o Estado é o receptor da ofensa tipificada como crime, sendo a punição o corolário desse sistema. Nesse sentido, as consequências da ação são pré-determinadas, de forma que vítima e ofensor pouco participam da solução aplicada ao caso concreto (ZEHR, 2008, p. 86). A verificação e o grau da culpa orientam a aplicação da punição.

Porém, constata-se que os sistemas penais atuais, fundamentados no paradigma retributivo, têm apresentado sérias disfunções, dentre as quais destacam-se: a superlotação carcerária; a não assunção de responsabilidades e a reincidência de delitos por parte dos infratores, dentre outras. Essas disfunções indicam a insuficiência desse paradigma em apresentar respostas satisfatórias para a resolução e mesmo para a prevenção de ocorrência de novos delitos, bem como de conscientizar os infratores acerca das consequências de sua conduta a e a repercussão negativa desta na esfera das vítimas.

Com o intuito de apresentar respostas a essas disfunções, alternativas internas aos sistemas penais têm sido pensadas (ZEHR, 2008, p. 89). No Brasil, por exemplo, cita-se a possibilidade de conciliação e aplicação de penas não privativas de liberdade no caso da ocorrência de infrações penais de menor potencial ofensivo (BRASIL, 1995).

Embora a necessidade de mudanças no sistema penal brasileiro seja incontestável, é preciso questionar a eficácia dessas mudanças em alcançar o pressuposto básico do paradigma retributivo, a saber, o "papel do Estado e da 
vítima na justiça" (ZEHR, 2008, p. 90), visto que nesse pressuposto reside um núcleo problemático e que subjaz a estrutura do sistema penal vigente.

Nesse trabalho pretende-se compreender a justiça restaurativa como uma das possíveis respostas às questões supramencionadas. O paradigma retributivo, que se pauta na retribuição da ofensa, na responsabilização individual e no negligenciamento dos interesses da vítima tem se mostrado insuficiente em lidar com a problemática apresentada. Soluções que apontem para uma responsabilidade coletiva, centrada nas pessoas e relacionamentos, orientadas para a construção de um futuro, e não na culpa pretérita, poderiam contribuir, de forma mais humana e digna, com o tratamento da criminalidade que se apresenta hoje no Brasil.

Sob o escopo de se perscrutar as razões para a aplicação da justiça restaurativa no tratamento de adolescentes autores de atos infracionais farse-á nesse trabalho um recorte com enfoque no sistema juvenil brasileiro. Esse recorte se justifica face a existência de importantes instrumentos jurídicos no arcabouço legal brasileiro, aplicados a adolescentes autores de atos infracionais, que mencionam princípios e valores relacionados às práticas restaurativas.

\section{Sobre o contexto do surgimento da justiça restaurativa}

Observa-se que a implementação da justiça restaurativa como proposta de se lidar com conflitos, judicializados ou não, ainda é um movimento recente, em construção, sendo que vários estudiosos têm se debruçado sobre o assunto (CRUZ, 2012, p. 34). Alguns países se encontram, entretanto, num estado mais avançado de consolidação da justiça restaurativa em relação ao Brasil.

Mylène Jaccoud ressalta a inspiração anglo saxônica da justiça restaurativa, bem como o seu amplo desenvolvimento em todo o mundo (JACCOUD, 2005, p. 163). A autora menciona também que outros teóricos 
utilizam diferentes termos para designar essa forma de solução de conflitos, tais como justiça transformadora, justiça relacional, justiça transformativa, justiça restaurativa comunal, justiça recuperativa e justiça participativa. Essa pluralidade de nomes demonstra que não há uma visão única da justiça restaurativa, mas sim diferentes concepções, consubstanciadas no conjunto de variadas práticas existentes em diversos países, com tradições jurídicas, culturais e sociais singulares.

As sociedades comunais (sociedades pré-estatais europeias e as coletividades nativas), face ao seu modelo de organização, "privilegiavam as práticas de regulamento social centradas na manutenção da coesão do grupo" (JACCOUD, 2005, p. 163). Assim, diante da transgressão de uma norma, buscava-se estabilizar o equilíbrio rompido com essa transgressão. Muito embora outras formas de punição, como a vingança ou morte, ainda perseverassem, essas sociedades se caracterizavam pela busca da solução dos conflitos, de forma rápida e eficaz (JACCOUD, 2005, p. 163). Nas resoluções preponderavam os interesses coletivos face aos individuais.

As práticas embasadas na justiça restaurativa, entretanto, não remontam apenas às sociedades pré-estatais e coletividades nativas, mas podem ser percebidas em alguns códigos decretados antes da primeira era cristã. Jaccoud destaca o Código de Hammurabi (1700 a.C) e de Lipit-Ishtar (1875 a.C), que prescreviam medidas de restituição para crimes contra bens. O Código Sumeriano (2050 a.C) e o de Eshunna (1700 a.C), por sua vez, previam a restituição nos casos de crime de violência (JACCOUD, 2005, p.164).

Essas práticas podem ser observadas também entre os povos colonizados nas Américas do Norte, do Sul, na África, na Áustria, na Nova Zelândia, assim como entre as sociedades pré-estatais europeias (JACCOUD, 2005, p. 164). Com o nascimento dos Estados-nação, fundamentado pela ideologia liberal das revoluções burguesas, houve a centralização do poder e a unificação do direito, com a sua instituição e codificação. Aos povos 
colonizados, diante do avanço exploratório dos países colonizadores, foi imposto o direito estatal dos Estados-nação, o que foi responsável pela redução das formas de solução negociadas de conflitos (JACCOUD, 2005, p. 164). Conforme assevera Boaventura de Sousa Santos,

[...] o Estado-nação tem sido a escala e o espaço-tempo mais central do Direito durante os últimos duzentos anos, particularmente nos países do centro do sistema mundial. Com o positivismo jurídico esta centralidade sociológica (mais ou menos intensa) foi transformada em uma concepção político-ideológica que converteu o Estado na fonte única e exclusiva do Direito (SANTOS, 2009, p. 52 - tradução livre).

Observa-se que apesar da imposição do sistema jurídico dos países colonizadores, o qual prevê a soberania e oficialidade do direito estatal, as práticas tradicionais de solução de conflitos dessas sociedades não foram totalmente extintas (JACCOUD, 2005, p. 164). Muitas dessas práticas foram mantidas, face à demanda dos membros dessas comunidades e aos problemas decorrentes da superlotação dos nativos em estabelecimentos penais e sócioprotetivos (JACCOUD, p. 164). Na Nova Zelândia, por exemplo, destacam-se as práticas restaurativas na sociedade Maori. Nessa sociedade, os whanau (famílias/famílias estendidas) e os hapu (comunidades/clãs) reúnem-se para resolver conflitos, bem como para "determinar como lidar com problemas que afetam a família ou a comunidade.” (MAXWELL, 2005, p. 279).

Face às preocupações dos Maori sobre a forma como as instituições na Nova Zelândia, que visavam o bem-estar infantil, bem como o sistema de justiça juvenil, retiravam os jovens e as crianças de suas casas, privando-os do contato com suas famílias estendidas e comunidades, os Maori passaram a exigir processos que se adequassem melhor à sua cultura, bem como "estratégias que permitissem às famílias sem recursos a possibilidade de cuidar de suas próprias crianças mais eficazmente” (MAXWELL, 2005, p. 279280). As reivindicações dos Maori culminaram, em 1989, na Nova Zelândia, na aprovação do Estatuto das Crianças, Jovens e suas Famílias, o que representou uma mudança significativa em relação à legislação anterior no 
que tange à forma de se responder ao abuso, ao abandono e aos atos infracionais (MAXWELL, 2005, p. 280). A nova legislação passou a incorporar as famílias nas decisões primárias sobre o que seria feito, concedendo-lhes, assim, a responsabilidade primária das decisões. Essas famílias passariam a receber apoio em seu papel de prestadores de serviços e outras formas apropriadas de assistência (MAXWELL, 2005, p. 280).

As reivindicações desses povos nativos para que as suas práticas fossem respeitadas dá-se também devido à presença nos estabelecimentos penais e sócio-protetivos de vários membros dessas comunidades. Essas reivindicações, por sua vez, são responsáveis pelo ressurgimento dos modelos restaurativos de solução de conflitos (JACCOUD, 2005, p. 164). Ocorre que a imposição por parte dos países colonizadores de um sistema de direito único e coercitivo não foi capaz de minar por completo o pluralismo jurídico existente nas sociedades pré-estatais e colonizadas.

O ressurgimento das práticas restaurativas na contemporaneidade responde às dificuldades e obstáculos em se lidar com a cultura de povos heterogêneos, com formas próprias de se lidar com conflitos e transgressões à normas. Essas formas têm sido recuperadas não apenas para dar conta da relação entre esses povos e o Estado moderno, mas também devido à incapacidade dos sistemas jurídicos penais atuais de lidar com os próprios obstáculos por ele criados.

Muito embora as práticas embasadas na justiça restaurativa tenham sido constantes nas sociedades coloniais pré-estatais, observa-se que essas práticas não se limitavam somente aos povos nativos, mas também às sociedades comunais (JACCOUD, 2005, p. 164). A título de exemplo, práticas restaurativas podem ser encontradas em algumas comunidades quilombolas brasileiras (CRUZ, 2012, p. 36). Rocha, citado por Cruz, assevera a abordagem coletiva dos conflitos por parte dessas comunidades quilombolas, bem como a forma como elas se organizam coletivamente para tratá-los (ROCHA, 2009; CRUZ, 2012, p.36). 
As práticas restaurativas, características dos povos nativos, préestatais e de sociedades comunais, englobam um conjunto de valores que dizem respeito às formas como os conflitos e transgressões aos regulamentos sociais são tratados, considerando-se sobremaneira os interesses coletivos face aos individuais, assim como a relação de igualdade entre todos nas tomadas de decisões, com vistas à manutenção da coesão do grupo.

No que tange à resolução de conflitos nas sociedades contemporâneas, precipuamente naqueles que resultam em crimes, observa-se uma crise sistêmica, demonstrada pela ineficiência das instituições carcerárias e as que executam as medidas socioeducativas em evitar a reincidência de crimes e atos infracionais por parte de adultos e adolescentes, especificamente. Há também uma debilidade em possibilitar que aja a efetiva assunção de responsabilidade por parte dos ofensores, o que teria o condão de diminuir a reincidência das transgressões às normas. Ainda em relação ao sistema de justiça penal brasileiro, a política criminal, calcada no modelo retributivo, falha sistematicamente na promoção da pacificação social. O encarceramento excessivo é banalizado, perdendo assim o seu caráter dissuasório (DE VITTO, 2005, p. 42).

Diante desse cenário, faz-se mister que outros métodos de solução de conflitos, que redundem ou não em crimes ou ato infracionais, sejam pensados, de forma a se buscar a pacificação e uma convivência social saudável e sustentável.

Nesse sentido, Faget, citado por Jaccoud, ressalta que existem fatores que reforçam o aparecimento da justiça restaurativa nas sociedades contemporâneas ocidentais, além das reivindicações dos povos nativos pelo respeito às suas concepções de justiça. Tratam-se dos movimentos: 1) de contestação das instituições repressivas; 2) da descoberta da vítima; 3) de exaltação da comunidade (FAGET, 1997; JACCOUD, 2005, p.164).

O movimento de contestação das instituições repressivas teve origem nas universidades americanas, tendo sido fortemente marcado pelos 


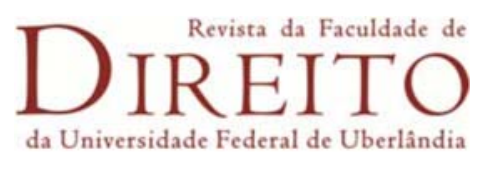

trabalhos da Escola de Chicago e de criminologia radical da Universidade de Berkeley. Ao focalizar a crítica às instituições repressivas, esse movimento questiona o papel dessas instituições no processo de definição do criminoso. Esse movimento encontra sustentação na Europa, onde trabalhos como o de Michel Foucault (Surveiller et punir: naissance de la prison, 1975), Françoise Castel, Robert Castell e Anne Lovel (La société psychiatrique avancée: le modèle américain,1979), Nils Christie (Limits to Pain, 1981) e Louk Hulsman (Peines perdues: le système pénal en question, 1982), defendem "recurso para uma justiça diferente, humanista e não punitiva" (JACCOUD, 2005, p. 165).

$\mathrm{Na}$ esteira das propostas desses pensadores, Louk Hulsman aduz:

\begin{abstract}
O sistema penal rouba o conflito das pessoas diretamente envolvidas nele. Quando o problema cai no aparelho judicial, deixa de pertencer àqueles que o protagonizaram, etiquetados de uma vez por todas como 'o delinquente' e 'a vítima' (HULSMAN, 1997, p. 82).
\end{abstract}

No que tange ao movimento da descoberta da vítima, conforme lembra Faget, citado por Jaccoud, ao final da Segunda Guerra Mundial, surge um discurso de cunho científico sobre as vítimas, denominado 'vitimiologia' (FAGET, 1997; JACCOUD, 2005, p. 38). Esse movimento, em princípio, segue o curso aberto pelo pensamento positivista, que não apenas caracteriza a criminologia à época, como se preocupa com as razões da vitimização, tentando identificar quais são os fatores que predispõem indivíduos a tornarem-se vítimas. Posteriormente, sensibilizados pelo discurso das vítimas, os críticos teóricos ao modelo retributivo preocupam-se com a ausência da vítima no processo penal, bem como com as suas necessidades. Assim,

[...] a intervenção estereotipada do sistema penal age tanto sobre a "vítima", como sobre o "delinquente". Todos são tratados da mesma maneira. Supõe-se que todas as vítimas têm as mesmas reações, as mesmas necessidades. O sistema não leva em conta as pessoas em sua singularidade. Operando em abstrato, causa danos inclusive àqueles que diz querer proteger (HULSMAN, 1997, p. 83-84).

Não obstante o movimento vitimista tenha influenciado a formalização dos princípios da justiça restaurativa, ele não participou diretamente do seu 
advento. Assim, Faget, citado por Jaccoud, propõem prudência na análise das relações desse movimento com a justiça restaurativa (FAGET, 1997; JACCOUD, 2005, p.165).

O terceiro movimento, denominado exaltação da comunidade, serviu de inspiração ao movimento restaurativo. O princípio da comunidade faz alusão "ao lugar que recorda as sociedades tradicionais nas quais os conflitos são menos numerosos, melhor administrados e onde reina a regra da negociação.” (FAGET, 1997, apud JACCOUD, 2005, p. 165).

Muito embora esses três movimentos tenham contribuído para o advento da justiça restaurativa, eles são incompletos. As críticas relativas ao modelo terapêutico, bem como as transformações que ocorreram dentro e fora do sistema penal são decisivas para o surgimento da justiça restaurativa (JACCOUD, 2005, p. 165-166). Dentre outros fatores, destaca-se a necessidade de reconstrução do sistema de regulação social, sob a perspectiva de um acompanhamento das transformações mais recentes no Direito em geral e de contensão da expansão do Direito Penal em seu viés mais repressivo. Ressalta-se ainda que essas transformações ocorrem em um contexto político-institucional de "crises e déficits": crise do modelo tradicional de justiça, ausência de comunicação entre o sistema de justiça e a sociedade, bem como déficit de participação popular na administração da justiça (SICA, 2006, p.1).

Diante desse quadro, observa-se que fatores internos e externos aos sistemas de Direito Penal são responsáveis pelo surgimento da justiça restaurativa. A ausência de soluções dialógicas dos conflitos, a crise no sistema de regulação social e o descrédito nas instituições jurídicas intensificam a necessidade de que outros métodos de solução de conflitos sejam pensados e (por que não) recuperados. Não apenas com o objetivo de diminuir o número de processos judiciais, mas, especialmente, no intuito de fundar uma outra lógica de inter-relação entre os seres humanos, mas digna, horizontal, dialógica e cidadã. 


\section{Configurações da justiça restaurativa}

Inexiste um conceito unânime de justiça restaurativa. Jan Froestad e Clifford Shearing atentam para a dificuldade em se encontrar um conceito único e restritivo para essa forma de solução de conflitos que, na década de 90, apresenta-se como modelo de referência para as reformas dos sistemas de justiça criminal (FROESTAD; SHEARING, 2005, p. 79). A justiça restaurativa institui-se como uma tentativa, segundo os autores, de olhar o crime sob novas lentes, fazendo referência à renomada obra Trocando as lentes, de Howard Zehr. Segundo Zehr, o crime é visto sob o modelo retributivo, incapaz de atender a muitas das necessidades da vítima e do ofensor. Assim, o processo penal falha porque não possibilita que os ofensores possam se responsabilizar por suas condutas, não coibi o crime, bem como negligencia as necessidades das vítimas (ZERH, 2010, p. 168).

A justiça restaurativa sustenta-se sobre três pilares (ZEHR, 2012). O primeiro pilar faz referência ao enfoque ao dano cometido. Diferentemente dos sistemas penais atuais, calcados na tradição retributiva (KONZEN, 2007, p. 101), cuja preocupação principal diante de um crime é que o ofensor responda penalmente pelo dano causado, a justiça restaurativa parte da concepção de que o crime gera um dano às pessoas e comunidades. Ao se ater ao dano, desloca-se o foco para a vítima e suas necessidades, que no processo penal são negligenciadas (ZEHR, 2012). Com isso,

\footnotetext{
[e]mbora a primeira preocupação deva ser com o dano sofrido pela vítima, a expressão 'foco no dano' significa que devemos também nos preocupar com o dano vivenciado pelo ofensor e pela comunidade. $\mathrm{E}$ isto deve nos levar a contemplar as causas que deram origem ao crime. O objetivo da Justiça Restaurativa é oferecer uma experiência reparadora para todos os envolvidos (ZEHR, 2012, p. 34).
}

Assim, embora as necessidades da vítima sejam centrais no processo restaurativo, não se pode descurar das necessidades do ofensor, que deve sim 


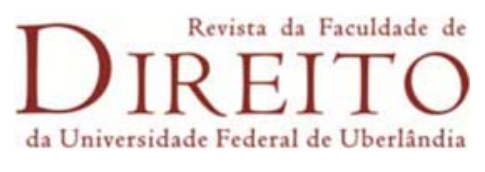

ser responsabilizado, bem como das necessidades da comunidade. Compreender as causas que deram origem ao crime ou ato infracional muitas vezes pode desvelar uma realidade permeada de contradições, de negação de direitos fundamentais, não apenas em relação aos adolescentes, mas também em relação aos adultos.

O segundo pilar da justiça restaurativa seriam as obrigações geradas pelos danos (ZEHR, 2012). Além da punição dos ofensores, faz-se necessário prover as condições para que estes possam se responsabilizar pelas consequências de seus atos, estimulando-os nessa direção. "Além disso, devem assumir a responsabilidade de corrigir a situação na medida do possível, tanto concreta quanto simbolicamente.” (ZEHR, 2012, p. 35).

O terceiro pilar seria o engajamento ou participação. Esse princípio concita vítimas, ofensores e comunidade, que possuem interesses específicos, a participarem do processo judicial, desempenhando assim um papel significativo. Estar à par de informações sobre os outros, bem como envolverse nas decisões consubstanciam o princípio do engajamento ou participação (ZEHR, 2012, p. 35).

Ao tratar das pessoas envolvidas nos processos judiciais, bem como a forma como se dá esse envolvimento, Zehr (2012) pontua que muito embora a justiça restaurativa admita a necessidade de autoridades externas ao caso e, algumas vezes, de decisões cogentes, processos cujas decisões tenham sido alcançadas mediante consenso, de naturezas participativa e inclusiva, são preferenciais, de forma que:

Um encontro presencial, face a face - precedido de preparação,
planejamento e salvaguarda adequados - via de regra constitui o
fórum ideal para a participação das pessoas diretamente
interessadas. [...] O encontro permite que vítima e ofensor ganhem
feições, façam perguntas um ao outro diretamente, e negociem um
modo de corrigir a situação (ZEHR, 2012, p. 37).

Nem sempre, entretanto, encontros diretos são possíveis e/ou desejáveis. Nesses casos, encontros indiretos, viabilizados por meio de cartas, vídeos gravados ou através de um representante da vítima, podem possibilitar 
a troca de informações e envolvimento das partes interessadas (ZEHR, 2012, p. 38).

Alguns autores sustentam que as configurações da justiça restaurativa podem ser delineadas, precipuamente, pelos valores que permeiam os processos restaurativos (FROESTAD; SHEARING, 2005, p. 79). Essa afirmação se justifica porque as práticas restaurativas têm sido utilizadas em diferentes países, com sistemas jurídicos e culturas diversos, de forma que fixar um conceito poderia limitar a sua amplitude e desconsiderar as diferentes formas seu desenvolvimento. Nesse sentido, na tentativa de especificar a justiça restaurativa, busca-se enfatizar a qualidade dos processos restaurativos (FROESTAD; SHEARING, 2005, p. 79).

Partindo-se da caracterização da justiça restaurativa pela qualidade dos processos restaurativos, a resolução da ONU n. 2002/12, que estabelece "Princípios Básicos para a Utilização de Programas de Justiça Restaurativa em Matéria Criminal” estatui, em seu tópico II, que trata da utilização de programas de justiça restaurativa, que

\begin{abstract}
[p]rocessos restaurativos devem ser utilizados somente quando houver prova suficiente de autoria para denunciar o ofensor e com o consentimento livre e voluntário da vítima e do ofensor. A vítima e o ofensor devem poder revogar esse consentimento a qualquer momento, durante o processo. Os acordos só poderão ser pactuados voluntariamente e devem conter somente obrigações razoáveis e proporcionais (ONU, 2002).
\end{abstract}

Essa Resolução apresenta-se como um importante instrumento, porque além de estatuir os princípios para utilização de programas de justiça restaurativa, concita os Estados membros "a inspirarem-se nos princípios básicos para programas de justiça restaurativa em matéria criminal no desenvolvimento e implementação de programas de justiça restaurativa na área criminal." (ONU, 2002).

No Brasil, o Conselho Nacional de Justiça (CNJ) estatuiu a Resolução n. 225, de 31/05/2016, que "Dispõe sobre a Política Nacional de Justiça Restaurativa no âmbito do Poder Judiciário e dá outras providências”. Essa 
Resolução representa um importante marco referencial para a justiça restaurativa no Brasil, estabelecendo algumas definições sobre conceitos como práticas e procedimentos restaurativos (art. $\left.1^{\circ}, \S 1^{\circ}\right)$, bem como sobre os princípios que orientam essas práticas.

No que concerne a legislação brasileira aplicada à adolescentes, o Estatuto da Criança e do Adolescente (ECA) bem como a Lei n. 12.594, de 18/01/2012, que institui o Sistema Nacional de Atendimento Socioeducativo (Sinase), estabelecem importantes institutos que aproximam o sistema de justiça juvenil brasileiro à abordagem da justiça restaurativa no tratamento de adolescentes autores de atos infracionais.

Após analisado o paradigma da justiça retributiva e da justiça restaurativa, o contexto de surgimento e as configurações dessa justiça, analisar-se-á a legislação brasileira aplicada ao adolescente autor de ato infracional. Essa análise será feita com o objetivo de estabelecer uma interface entre institutos dessa legislação e sua aproximação com preceitos da justiça restaurativa.

\section{Os fundamentos da aplicação da justiça restaurativa no sistema de justiça juvenil brasileiro}

O Estatuto da Criança e do Adolescente (ECA), instituído pela Lei n. 8.069, de 13/07/1990, encontra-se apoiado em três eixos centrais denominados Sistemas de Garantias. Esse sistema é harmônico, podendo ser acionado sucessiva ou simultaneamente (SARAIVA, 2010, p. 64).

O primeiro sistema, denominado sistema primário de garantias, consiste nos fundamentos da política pública com vistas a atender toda a população infanto-juvenil brasileira, possuindo assim caráter universal. Os fundamentos dessa política de atendimento encontram-se expressos nos artigos 86 e 87 do ECA. O segundo sistema, intitulado sistema secundário de garantias, objetiva atender a crianças e adolescentes que se encontram em 
situação de vulnerabilidade, com seus direitos fundamentais desrespeitados. Este sistema encontra-se embasado nos artigos 98, 101 e 136 do Estatuto. A criança, quando autora de ato infracional, receberá medida protetiva, nos termos do art. 105 do ECA. Essas medidas são aplicadas pelo Conselho Tutelar (art. 136 do ECA). Os adolescentes autores de ato infracional também poderão receber subsidiariamente essas medidas, conforme estabelece o art. 112, inc. VII do Estatuto. O terceiro sistema, denominado sistema terciário de garantias, é concernente ao adolescente em conflito com a lei. Os dispositivos relativos a esse sistema iniciam-se no art. 103 do ECA, englobando as medidas socioeducativas a serem aplicadas aos adolescentes autores de atos infracionais (SARAIVA, 2010, p. 64). Essas medidas encontram-se elencadas no art. 112 do ECA.

Dentre as medidas socioeducativas e os princípios que as regem, previstas no art. 100, destaca-se nesse trabalho as que, direta ou indiretamente, contribuem com a aproximação da justiça restaurativa com o sistema de justiça juvenil brasileiro. O art. 112, inc. II do ECA estatui que uma das medidas socioeducativas a ser aplicada ao adolescente autor de ato infracional é a obrigação de reparar o dano. Essa medida vai de encontro a um dos princípios da justiça restaurativa, que é o enfoque no dano e nas necessidades da vítima.

No paradigma instaurado pela justiça retributiva, a vítima ocupa um papel secundário, visto que o enfoque está "em dar aos ofensores o que eles merecem.” (ZEHR, 2012, p. 34). Como o Estado desempenha o papel de principal violado com o dano ocorrido, há uma preocupação em se punir o ofensor, sendo as consequências vivenciadas com o dano pela vítima, e também pela comunidade, alijadas do processo. Sob o enfoque do paradigma restaurativo a preocupação reside no dano vivenciado pela vítima, com o objetivo de repará-lo.

Sabe-se que a comunidade também sofre as consequências do dano, haja vista que há uma interconexão entre os membros que a compõem, e que 
os danos que afetam a uma pessoa diretamente reverberam em outras pessoas, sejam as vítimas secundárias, como parentes da vítima, amigos, seja a comunidade na qual ela se encontra inserida. Preocupar-se com os danos de todos os envolvidos no processo também inclui os danos sofridos pelo ofensor, o que conduz à indagação sobre os fatores que deram origem ao delito. Assim, torna-se importante olhar para as possíveis causas do delito cometido pelo adolescente, com o objetivo de se atacar os fatores que possam contribuir e potencializar a ocorrência de atos infracionais.

Nesse sentido faz-se mister destacar a abordagem interdisciplinar que o Direito juvenil requer. A psicologia, a sociologia, a pedagogia e o direito, por exemplo, são áreas que podem contribuir, e de fato já vêm dando a sua contribuição, para a compreensão do ato infracional e de como tratar o adolescente em conflito com a lei, que se apresenta, muitas das vezes, conforme acentua Antônio Carlos Gomes da Costa, "como uma ilha cercada de omissões" (COSTA, 1990, p. 74).

$\mathrm{O}$ art. 116 do ECA, ao tratar especificamente da medida socioeducativa de reparação do dano, prevê que quando se tratar de ato infracional com reflexos patrimoniais, o juiz poderá determinar que o adolescente de alguma forma compense a vítima, seja por meio da restituição da coisa ou ressarcimento do dano.

Esse artigo é consentâneo com o princípio da justiça restaurativa de se enfocar o dano vivenciado pela vítima. Ressalta-se assim que no caso de ato infracional com reflexo patrimonial existe a possibilidade de restituição da coisa, ressarcimento do dano, ou, por outro meio, compensar o prejuízo da vítima. Ou seja, o enfoque está na reparação desta, na sua necessidade.

Muito embora faça-se necessário perscrutar as possíveis causas da ocorrência de atos infracionais, não se pode descurar da responsabilização do ofensor. Assim,

[n]o âmbito geral, responsabilizar significa assegurar-se de que o ofensor seja punido. No entanto, se o crime for visto essencialmente 
como um dano, a responsabilização significa que o ofensor deve ser estimulado a compreender o dano que causou. Os ofensores devem começar a entender as consequências de seu comportamento. Além disso, devem assumir a responsabilidade de corrigir a situação na medida do possível, tanto concreta quanto simbolicamente (ZEHR, 2012, p. 35).

Nessa perspectiva, a responsabilidade deve ser compreendida não como necessidade de punição e culpa, voltada para os atos pregressos, mas como assunção de responsabilidade pelos atos que causaram danos à outra pessoa e que, nessa perspectiva, devem ser corrigidos. A participação do ofensor, ofendido e comunidade, quando possível, reforça a necessidade de se corrigir os danos causados, de forma que a decisão que decorra do processo restaurativo seja uma decisão construída, envolvendo as partes interessadas, e não uma decisão coercitiva, unilateral, sem que as partes possam se responsabilizar, bem como informar-se dos resultados do processo.

No Direito juvenil essa abordagem focada no dano e no porvir, em detrimento da culpa voltada para o passado, deve ser reforçada porque o adolescente de hoje encontra-se em processo de desenvolvimento para a vida que está porvir. Não se pode vilipendiar o fato que a adolescência é um momento peculiar na vida do ser humano, que por estar em processo de desenvolvimento, possui direitos comuns aos dos adultos, além de outros que provém dessa condição. Crianças e adolescentes trazem em si uma projeção da sociedade que virá, fazendo-se necessário que o seu tratamento, conforme ditame constitucional, previsto no caput do art. 227 da Constituição, seja feito com absoluta prioridade.

A responsabilização vai de encontro a um dos pilares da justiça restaurativa, segundo o qual "Males ou danos resultam em obrigações" (ZEHR, 2012, p. 35). O dano causado pelo adolescente com a realização do ato infracional deve ser corrigido, sendo necessário assim que haja a imputação e consequente responsabilização dele pelo seu ato. O processo restaurativo é fundamental para viabilizar essa assunção de responsabilidade por parte do adolescente, por meio do diálogo, do respeito e da escuta ativa da vítima e das 
demais partes envolvidas. A justiça restaurativa, nesse sentido, possibilita um encontro profícuo, no qual o ofensor, bem como a comunidade envolvida, é encorajado a assumir o seu papel, as suas ações. Nesse ambiente, por meio de um processo dialógico, novos sentidos são atribuídos ao ato infracional, que assume outros contornos e significados, além de uma conduta legalmente tipificada, pela qual se estabelece uma punição.

Observa-se ainda que a responsabilização do adolescente se constitui também como um dos princípios da doutrina da proteção integral. Não é porque o adolescente é inimputável, não respondendo perante a justiça penal comum, que ele não será responsabilizado. A assunção de responsabilidade é importante para a sua formação e desenvolvimento. A forma como ela se dará, seja de forma cogente, sem a compreensão da repercussão da ação sobre a esfera da vítima e da comunidade, ou de forma coletiva, envolvendo as partes interessadas na solução do conflito, é determinante para a caracterização do processo como restaurativo.

Essa participação das partes interessadas constitui-se também, conforme mencionado acima, como um pilar da justiça restaurativa (ZEHR, 2012 , p. 35). Tanto a vítima, quanto o ofensor e a comunidade possuem interesse direto na solução do conflito instaurado, devendo para isso existir a troca de informações uns sobre os outros (ZEHR, 2012, p. 35), bem como haver a decisão conjunta para o caso concreto, de forma que o sentimento de justiça possa ser vivenciado por todos. Renato Campos Pinto De Vitto enfatiza que

[o] modelo de justiça restaurativa busca intervir positivamente em todos os envolvidos no fenômeno criminal. Pretende, destarte, tocar a origem e causa daquele conflito, e a partir daí possibilitar o amadurecimento pessoal do infrator, redução dos danos aproveitados pela vítima e comunidade, com notável ganho na segurança social (VITTO, 2005, p. 49).

Assim, perscrutando-se as origens do conflito e os danos por ele causados, pretende-se envolver as principais partes interessadas, de forma que todos possam contribuir com a construção da decisão oriunda do processo 
restaurativo, responsabilizando-se por ela. A responsabilidade, assim, desloca-se da perspectiva individual, tornando-se coletiva.

Em consonância com o princípio do engajamento ou participação das partes interessadas (ZEHR, 2012, p. 35), o art. 100 do ECA, Lei no 8.069 de 13 de julho de 1990, ao tratar da aplicação das medidas protetivas e socioeducativas, estabelece que "[n]a aplicação das medidas levar-se-ão em conta as necessidades pedagógicas, preferindo-se aquelas que visem ao fortalecimento dos vínculos familiares e comunitários" (BRASIL, 1990).

Nessa perspectiva, o Estatuto da Criança e do Adolescente, ao estatuir que o fortalecimento dos vínculos familiares e comunitários deverão ser priorizados na aplicação das medidas socioeducativas, reforça a importância desses vínculos para o adolescente. A relação com a família e a comunidade é importante porque gera no adolescente um sentimento de pertencimento, de que ele/ela não está sozinho. Essas pessoas representam referenciais significativos, e o apoio delas ao adolescente é fundamental para que ele possa ser auxiliado a vislumbrar outros horizontes, que não a delinquência juvenil. Ressalta-se o empoderamento propiciado pelo processo restaurativo, pois as partes tornam-se responsáveis pelas decisões tomadas por elas. Essa participação efetiva das partes é consentânea com o princípio da democracia participativa, próprio de um Estado Democrático de Direito.

$\mathrm{Na}$ esteira da participação e do engajamento das partes interessadas, é de bom alvitre mencionar o art. 227 da Constituição Federal de 1988, que estabelece ser dever da família, da sociedade e do Estado, com absoluta prioridade, assegurar à criança, ao adolescente e ao jovem os direitos fundamentais previstos no caput do artigo, tais como o direito à vida, à saúde, à alimentação, à educação, ao lazer, à profissionalização, à cultura, à dignidade, ao respeito, à liberdade e à convivência familiar e comunitária. Assim, existe uma responsabilidade solidária da família, da sociedade e Estado em garantir que crianças e adolescentes tenham os seus direitos fundamentais efetivados, de forma que possam exercer a sua cidadania plena, 


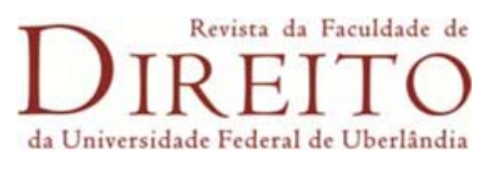

livres de qualquer forma de discriminação e opressão. Os processos restaurativos propiciam esse ambiente, no qual, sempre que possível, vítima, comunidade e representantes dos órgãos estatais participam, com a função de dar apoio ao adolescente, bem como de auxiliá-lo e colaborar com a efetivação dos seus direitos. Exsurge, nessa perspectiva, a necessidade do trabalho em rede, integrado, com o escopo de dar suporte ao adolescente, e de promover a efetivação dos seus direitos fundamentais.

Eduardo Rezende Melo, ao se referir ao modelo da justiça restaurativa, afirma que

[...] um tal modelo não pode prescindir de um envolvimento comunitário para sua resolução e da intervenção efetiva de uma rede de atendimento fundada em políticas públicas voltadas a todos, que dê amparo às necessidades outras que entrem em questão naquele primeiro momento. São questões que, para além de uma mera divergência interpessoal, podem envolver aspectos sociais que demandarão não apenas a compreensão por parte da vítima, mas também da comunidade do entorno em que se dá o conflito. (MELO, 2005, p.66).

A necessidade da articulação em rede dos segmentos que atuam em prol dos direitos fundamentais de adolescentes, destacando-se os órgãos do Sistema de Justiça, Ministério Público e Poder Executivo é fundamental para esses direitos sejam efetivados, em consonância com a doutrina da proteção integral, que encontra guarida no art. 227 da Constituição Federal.

\section{Conclusão}

Refletir sobre outras formas de tratar os crimes e atos infracionais têm sido uma prática constante em vários países cujo paradigma retributivo constitui-se como pilar do sistema de justiça penal. A superlotação carcerária, a reincidência de crimes e atos infracionais, a não assunção de responsabilidade subjetiva, e não apenas formal, por parte de autores de delitos, são fatores que contribuem para a ineficácia das respostas oferecidas pelo sistema de justiça penal dos adultos e adolescentes. 
Outras formas de solução de conflitos, judicializados ou não, têm sido elaboradas e implementadas em diferentes países, dentre eles o Brasil. Essas alternativas, muito embora não substituam por completo o paradigma retributivo de justiça, constituem-se como instrumentos que ventilam outros referenciais, mais coletivos, racionais e democráticos. É nesse contexto que emerge a justiça restaurativa. Não como uma resposta a todas as vicissitudes dos sistemas calcados no paradigma retributivo, mas como uma possibilidade de humanização das medidas aplicadas aos autores de delitos.

A possibilidade de utilização dessa forma de solução de conflitos no Brasil é reforçada ao se considerar o contexto dos adolescentes, cuja legislação, embasada na doutrina da proteção integral, apregoa a necessidade de se assegurar a integralidade de seus direitos, com vistas a se assegurarlhes um desenvolvimento promissor. A legislação brasileira aplicada aos adolescentes autores de atos infracionais institui preceitos que possibilitam a aplicação da justiça restaurativa com esses adolescentes, respeitando-se concomitantemente os direitos e garantias previstos no direito processual.

A participação das partes interessadas na resolução dos conflitos e atos infracionais pode, dentre outras vantagens, ter o condão de reforçar o sentimento de pertencimento desses adolescentes, fortalecendo os seus referenciais, tão necessários ao processo de seu desenvolvimento. Concomitantemente, a possibilidade de atuação da rede de proteção dos direitos desses adolescentes pode garantir a efetivação de direitos fundamentais, principalmente em contextos nos quais as violações de direito, aliada à desigualdade social, são tão pujantes, como no Brasil.

\section{Referências}

BRASIL. Constituição da República Federativa do Brasil de 1988. Diário Oficial da União, Brasília, DF, $05 \quad$ out. $1988 . \quad$ Disponível em: http://www.planalto.gov.br/ccivil_03/Constituicao/Constituicao.htm . Acesso em: 04 set. 2019. Lei $\mathrm{n}^{\circ}$ 8.069, de 13 de julho de 1990. Dispõe sobre o Estatuto da Criança e do Adolescente e dá outras providências. Diário Oficial da União, Brasília, DF, 27 set. 1990. Disponível em: http://www.planalto.gov.br/ccivil_03/Leis/L8069.htm. Acesso em: 04 set. 2019. 
Lei $\mathrm{n}^{\circ}$ 9.099, de 26 de setembro de 1995. Dispõe sobre os Juizados Especiais Cíveis e Criminais e dá outras providências. Diário Oficial da União, Brasília, DF, 27 set. 1995. Disponível em: http://www.planalto.gov.br/ccivil_03/Leis/L9099.htm. Acesso em: 04 set. 2019.

Lei ${ }^{\circ} 12.594$, de 18 de janeiro de 2012. Institui o Sistema Nacional de Atendimento Socioeducativo (Sinase), regulamenta a execução das medidas socioeducativas destinadas a adolescente que pratique ato infracional; e altera as Leis $\mathrm{n}^{\circ} \mathrm{s} 8.069$, de 13 de julho de 1990 (Estatuto da Criança e do Adolescente); 7.560, de 19 de dezembro de 1986, 7.998, de 11 de janeiro de 1990, 5.537, de 21 de novembro de 1968, 8.315, de 23 de dezembro de 1991, 8.706, de 14 de setembro de 1993, os Decretos-Leis ${ }^{\circ} \mathrm{s} 4.048$, de 22 de janeiro de 1942, 8.621, de 10 de janeiro de 1946, e a Consolidação das Leis do Trabalho (CLT), aprovada pelo Decreto-Lei $\mathrm{n}^{\mathrm{o}}$ 5.452, de $1^{\mathrm{o}}$ de maio de 1943. Diário Oficial da União, Brasília, DF, 20 dez. 2012. Disponível em: http://www.planalto.gov.br/CCIVIL_03/_Ato2011-2014/2012/Lei/L12594.htm. Acesso em: 04 set. 2019.

. Ministério da Justiça e Segurança Pública. Diagnóstico Sistema Prisional

Brasileiro. Brasília, DF., 2016. Disponível em: file:///C:/Users/natal/AppData/Local/Packages/Microsoft.MicrosoftEdge_8wekyb3d8bbwe/Te mpState/Downloads/Apresentacİ§aI $f_{0} \% 20$ Diagnostico\%20MSP\%20(14).pdf. Acesso em: 04 set. 2019.

Ministério da Justiça e Segurança Pública. Levantamento Nacional de Informações Penitenciárias: Atualização - Junho de 2017. Brasília, DF., 2017.

CONSELHO NACIONAL DE JUSTIÇA (CNJ). Programa Nacional: A execução das medidas socioeducativas de internação. Programa Justiça ao Jovem. Brasília, DF., 2012. Disponível em: http://www.cnj.jus.br/images/programas/justica-aojovem/panorama_nacional_justica_ao_jovem.pdf . Acesso em: 04 set. 2019.

COSTA, Antônio Carlos Gomes da. Infância, Juventude e Política Social no Brasil. Brasil-Criança Urgente. São Paulo: Ed. Columbus Cultural, 1990.

CRUZ, Gizele. Ampliando as lentes: experiências de justiça restaurativa em Minas Gerais. 2012. 132 f. Dissertação (Mestrado em Direito) - Programa de Pós-Graduação da Faculdade de Direito, Universidade Federal de Minas Gerais, Belo Horizonte, 2012.

DE VITTO, Renato Campos Pinto. Justiça Criminal, Justiça Restaurativa e Direitos Humanos. In: SLAKMON, C.; DE VITTO, R; PINTO, R.S.G. (Orgs.). Justiça restaurativa. Brasília - DF: Ministério da Justiça e Programa das Nações Unidas para o Desenvolvimento - PNUD, 2005. cap. 2, p. 41-51.

FAGET, Jacques. La médiation: Essai de politique pénale. Ramonville Saint-Agne: éditions Erès, 1997.

FROESTAD, J; SHEARING, C. O Modelo Zwelethemba de Resolução de Conflitos. In: SLAKMON, C.; DE VITTO, R; PINTO, R.S.G. (Orgs.). Justiça restaurativa. Brasília - DF: Ministério da Justiça e Programa das Nações Unidas para o Desenvolvimento - PNUD, 2005. cap. 4, p. 79-123.

HUlSMAN, L.; CELIS, Jacqueline Bernat de. Penas Perdidas: O sistema penal em questão. 2. ed. Niteroi, RJ: Luam Editora, 1997.

JACCOUD, Mylène. Princípios, tendências e procedimentos que cercam a justiça restaurativa. In: SLAKMON, C.; DE VITTO, R; PINTO, R.G. (Orgs.). Justiça restaurativa. Brasília - DF: Ministério da Justiça e Programa das Nações Unidas para o Desenvolvimento, 2005. cap. 7, p. 163-186.

MAXWELL, Gabrielle. A Justiça Restaurativa na Nova Zelândia. In: SLAKMON, C.; DE VITTO, R; PINTO, R.S.G. (Orgs.). Justiça restaurativa. Brasília - DF: Ministério da Justiça e Programa das Nações Unidas para o Desenvolvimento - PNUD, 2005, cap. 13, p. 279-293. 


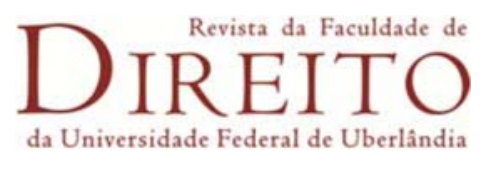

MELO, Eduardo Rezende de. Justiça restaurativa e seus desafios histórico-culturais: Um ensaio crítico sobre os fundamentos ético-filosóficos da justiça restaurativa em contraposição à justiça retributiva. In: SLAKMON, C.; DE VITTO, R; PINTO, R.S.G. (Orgs.). Justiça restaurativa. Brasília - DF: Ministério da Justiça e Programa das Nações Unidas para o Desenvolvimento - PNUD, 2005, cap. 3, p. 53-78.

KONZEN, Afonso Armando. Justiça restaurativa e ato infracional: desvelando sentidos no itinerário da alteridade. Porto Alegre: Livraria do Advogado, 2007.

KUHN, Thomas Samuel. A estrutura das revoluções científicas. São Paulo: Editora Perspectiva, 1998.

Organização das Nações Unidas (ONU). Resolução $n^{\circ}$ 2002/12, de 24 de julho de 2002. Regulamenta os princípios básicos para a utilização de Programas de Justiça Restaurativa em Matéria Criminal. Disponível em: http://www.refworld.org/cgibin/texis/vtx/rwmain?docid=46c455820. Acesso em: 04 set. 2019.

ROCHA, Gabriela de Freitas Figueiredo. As comunidades quilombolas em foco: uma análise sobre direitos humanos na relação entre emancipação social e interculturalidade. 2009. Monografia (Conclusão de curso). Universidade Federal de Minas Gerais, Faculdade de Direito, Belo Horizonte.

SANTOS, Boaventura de Sousa. A crítica da razão indolente: contra o desperdício da experiência. 7. ed. São Paulo: Cortez, 2009.

SARAIVA, João Batista Costa. Compêndio de direito penal juvenil: adolescente e ato infracional. 4. ed. rev. e amp. Porto Alegre: Livraria do Advogado Editora, 2010.

SICA, Leonardo. Bases para o modelo brasileiro de Justiça Restaurativa. In: SLAKMON, C.; MACHADO, M.R.; BOTTINI, P.C. (Orgs.). Novas direções na governança da Justiça e da Segurança Brasília-DF: Ministério da Justiça, 2006. Disponível em: < https://aplicacao.mpmg.mp.br/xmlui/bitstream/handle/123456789/151/Bases\%20para\%20mo delo\%20brasileiro_Sica.pdf?sequence=1>. Acesso em: 04 set. 2019.

ZEHR, Howard. Trocando as lentes: um novo foco sobre o crime e a justiça. São Paulo: Palas Athena, 2008.

Justiça Restaurativa. Tradução Tônia Van Acker. São Paulo: Palas Athena, 2012.

Artigo recebido em: 04/09/2019.

Aceito para publicação em: 14/06/2020. 